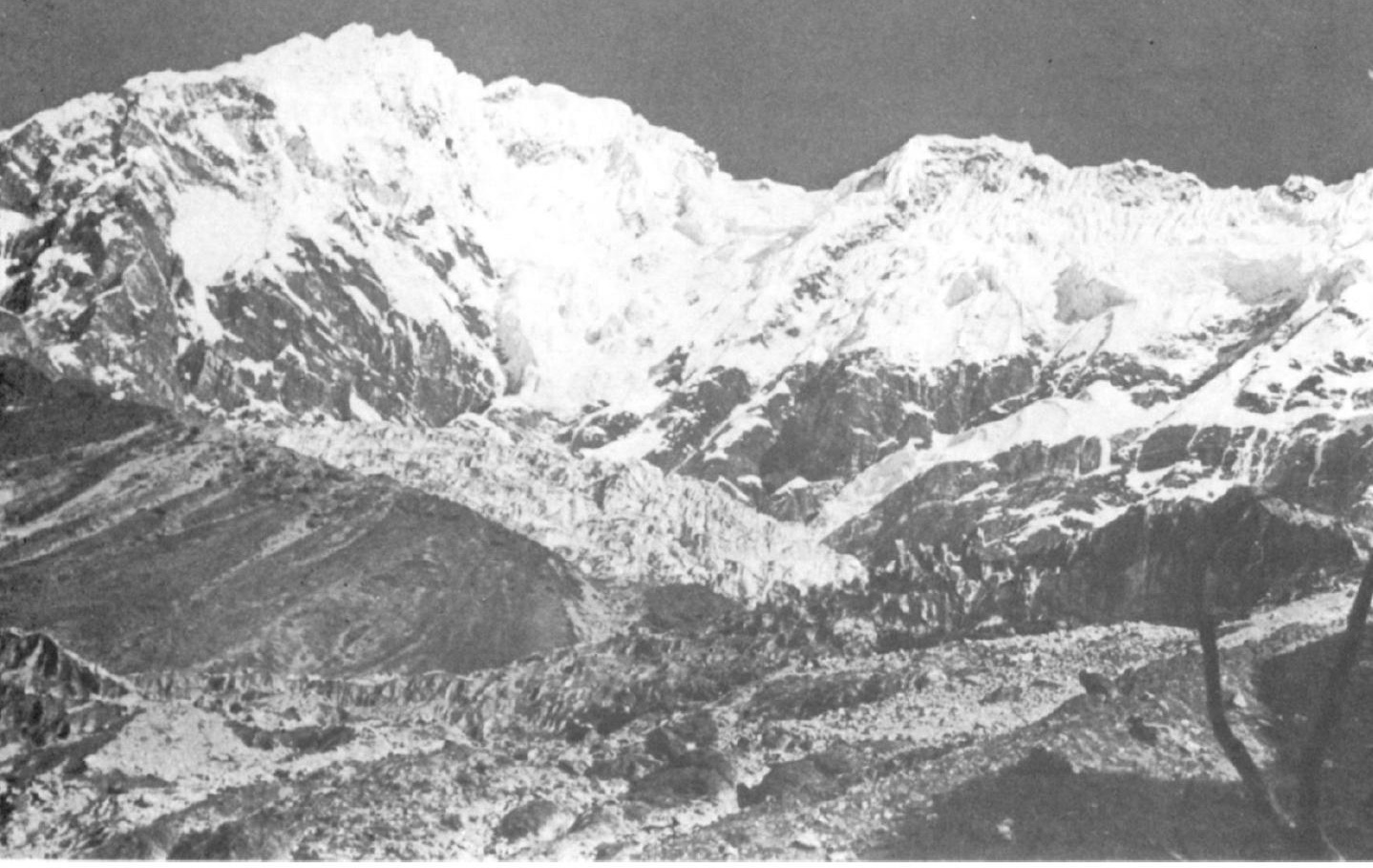

\title{
Tahr in a Nepal National Park
}

\section{Michael J. B. Green}

The Himalayan tahr Hemitragus jemlahicus occurs along the southern flanks of the Himalaya, from the Pir Panjal Range in northern India eastwards through Nepal to Sikkim, between $1500 \mathrm{~m}^{12}$ and $5200 \mathrm{~m} .{ }^{2}$ It is also reported as being 'not uncommon' at $1500-2100 \mathrm{~m}$ in southwest Bhutan. ${ }^{6}$ It is the only one of the three surviving tahr species that is not endangered. In Nepal its formerly continuous distribution has been disrupted by traditional land-use practices, which are spreading due to the increasing human population, and some hunting. Schaller mapped 14 populations known to occur in Nepal, but many more undoubtedly exist. 11

Gazetted in April 1976, Langtang covers $1710 \mathrm{sq} \mathrm{km}$ and is the largest of Nepal's four national parks. It extends from just $32 \mathrm{~km}$ north of Kathmandu right up to the Chinese (Tibetan) border, ranging from sub-tropical forest at $792 \mathrm{~m}$ to the sacred peak of I .angtang Lirung at $7245 \mathrm{~m}$. An indigenous human population of about 16,250 people inside the park depends on the natural resources for firewood, timber, pasture and agricultural land. Successful management, therefore, depends on reconciling the conflicting needs of the wildlife and the people. ${ }^{1}$ As part of its programme the Durham University Himalayan Expedition studied the Himalayan tahr in the upper section of the I.angtang Valley between April 1976 and April 1977.5

The tahr occur on the north side of the valley, above the forest level, between $3500 \mathrm{~m}$ and $5000 \mathrm{~m}, 1$ amidst a variety of vegetation types. The lower slopes of the

Above: LANGTANG. In the foreground an alp grazed by tahr but inaccessible to livestock. 


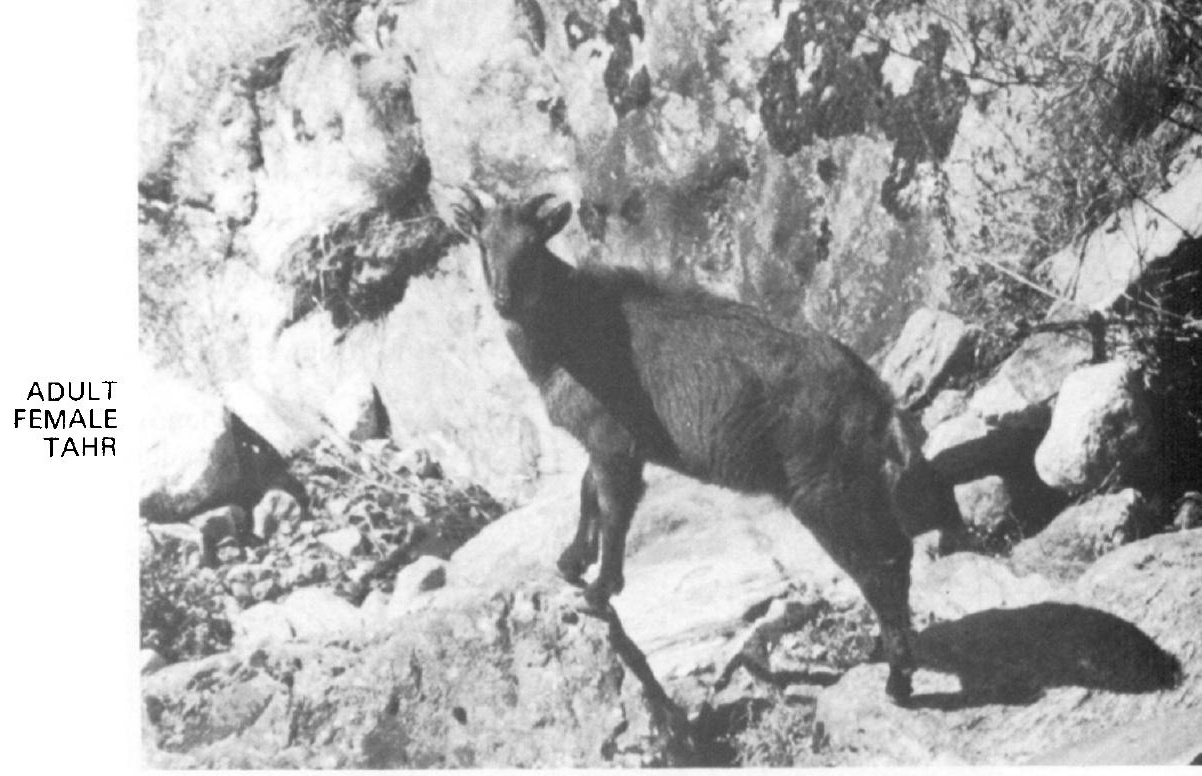

sub-alpine zone are covered by dense thickets of Caragana nepalensis, Berberis spp., Rosa spp. and Rhododendron lepidotum. Above these are precipitous cliffs where herbs, grasses and sedges are restricted to ledges and crevices, and higher still, in the alpine zone, the dominant shrubs are Cotoneaster microphylla, Ephedra gerardiana and Juniperus spp. on the drier south-facing slopes, with $R$ hododendron anthopogon and $R$. setosum on the damper, east-facing slopes. Herbs are common and tussocks of grasses and sedges abundant. Above $4300 \mathrm{~m}$ shrubs are absent, but herbs, grasses, sedges and cushion plants are common.

The Himalayan tahr has been described as both a forest animal 8 and also as an inhabitant of the sub-alpine zone between $3900 \mathrm{~m}$ and $5200 \mathrm{~m} .8$ In fact its distribution is not so limited. Schaller observed tahr in various vegetation types between $2500 \mathrm{~m}$ and $4400 \mathrm{~m},{ }^{10}$ and the evidence here also suggests that the species occupies a wider altitudinal range than was previously believed. In the lower part of the I angtang Valley, tahr were seen in Abies spectabilis and Quercus semicarpifolia forest as low as $2700 \mathrm{~m}$. Other herbivores in the I.angtang Valley include Himalayan musk deer Moschus moschiferus moschiferus, and domestic livestock - yak, cattle, sheep and goats. The musk deer chiefly inhabit Betula utilis and Rhododendron campanulatum forest on the south side, and their overlap with tahr is therefore minimal. I,ivestock, however, range over any of the tahr habitat accessible to them.

The complete absence of spoor indicates that large carnivores no longer occur within the study area, although leopard Panthera pardus and wild dog Cuon alpinus inhabit the lower part of the Iangtang Valley. In their first few days of life young tahr may fall prey to martens, foxes or large raptors, but such predators usually take rodents and small birds which, being lighter, are easier to carry off. Hunting was probably never a serious cause of mortality, and in recent years it has ceased. The inhabitants of Langtang village are Buddhists and do not kill tahr, or any other wild or domestic animal. The establishment in 1953 of a cheese factory above I angtang village brought in European and Hindu workers from Kathmandu who shot tahr, but that stopped in the autumn of 1973.

Tahr range in groups of up to 77 animals, but 15 is the average number. Groups mainly consist of adult males or adult females and juveniles except 
during the winter rut when groups of all ages and both sexes predominate. Although adult females and juveniles occupy the same ranges throughout the year, they make daily movements of about $700 \mathrm{~m}$ vertically. The lower cliffs and gullies provide overnight shelter, but the higher alps afford better grazing in the daytime. Adult males, however, rarely descend to lower altitudes but tend to move laterally to and fro each day.

Tahr are most active in the early morning and late afternoon, when they are usually feeding; midday is the time for resting. Over the year adult females and juveniles spend on average 70 per cent of the daytime feeding; with adult males during the rut this figure drops to about 40 per cent, as much time is spent in courtship. Analyses of faeces showed an average consumption over the year of 34 per cent grasses, 21 per cent sedges, 38 per cent herbs and shrubs, 4 per cent ferns, and 4 per cent mosses, but there were significant seasonal differences. For instance, in the winter they supplemented their diet with small amounts of mosses and ferns, presumably because other foods were less readily available.

Two tahr populations, referred to as Langtang and Yala, occur in the upper Langtang Valley, separated by a small glacial valley to which local people come with their livestock during the summer monsoon. Glaciers and moraines are not a physical barrier, but the presence of humans undoubtedly inhibits movement between the two populations, as tahr were never seen in the intervening valley. It is likely, therefore, that the populations represent fairly distinct breeding units, although solitary adult males may occasionally wander between the two. The I.angtang and Yala populations comprise about 170 and 46 animals respectively, although both occupy similarly sized areas of seven sq $\mathrm{km}$. The difference is probably because the Langtang population's terrain is largely inaccessible to livestock, whereas Yala's range is grazed by domestic animals for much of the Langtang National Park Opposite: Langtang Lirung

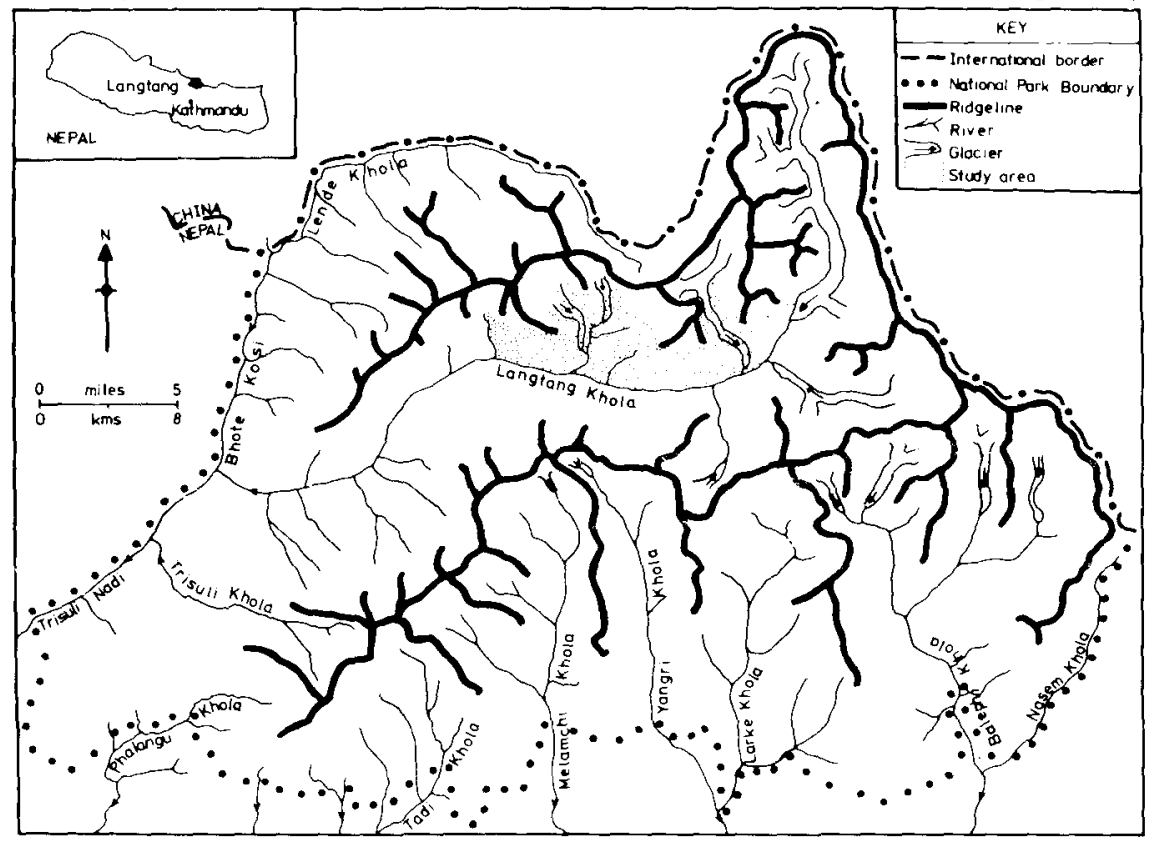




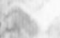

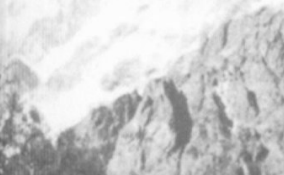

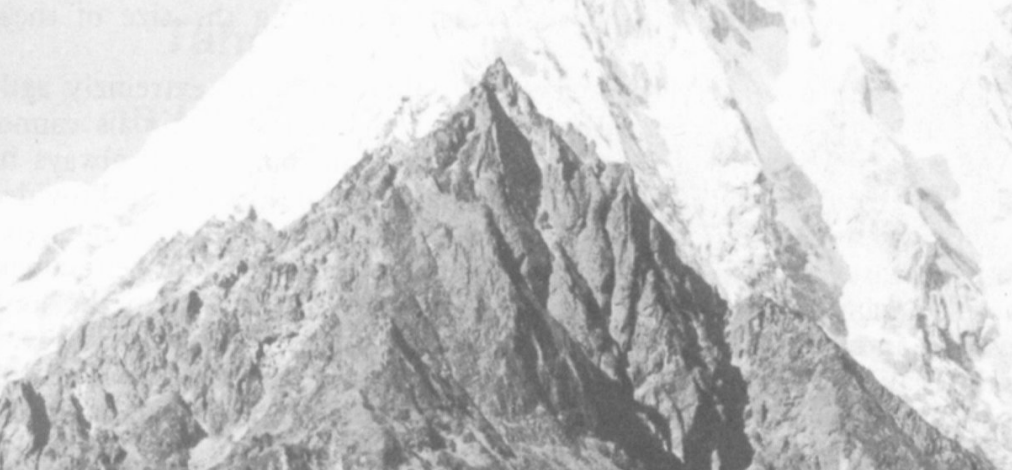
$3 x$

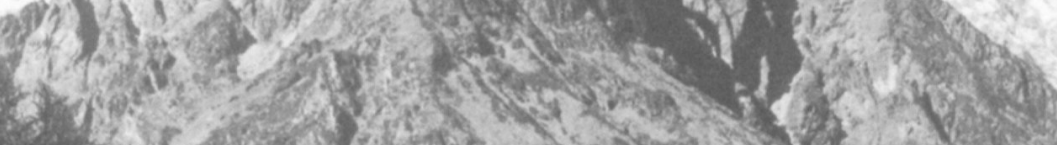

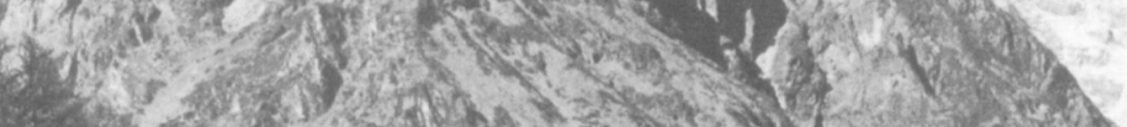

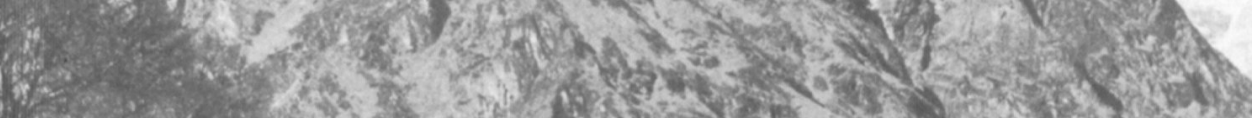

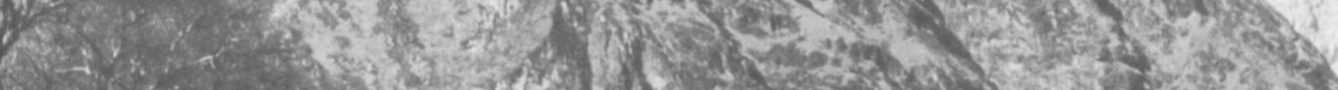
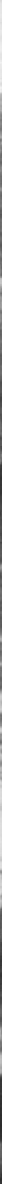
year; the Yala range supports ten times more sheep and eight times more cattle than the I.angtang range. As there is no natural predation or hunting within the study area, food is probably the principal factor limiting the size of these populations.

Fortunately, from a conservation viewpoint, the tahr is an extremely agile animal and able to inhabit precipitous terrain that domestic animals cannot reach. And as certain parts of the I Langtang and Yala ranges will always be inaccessible to livestock, both these tahr populations should survive. Provided the two populations remain large enough to be viable breeding units, no active conservation measures are needed. To propose that livestock should be removed from the Yala range, so that the tahr could increase, would harm the local economy and increase the people's present hostility to the park. However, overgrazing is already a problem, causing erosion and deterioration in the quality of the pastures. If it is not controlled it will adversely affect both wild and domestic populations.

\section{Acknowledgments}

The Himalayan tahr was studied in the I,angtang National Park under the auspices of the Durham University Himalayan Expedition, whose sponsors, including the FPS, are detailed elsewhere (Borradaile et al. 1977). Permission to work in the I angtang National Park was granted by the Ministry of Forests. The author wishes to thank FPS for providing an additional grant to enable him to write up his field work, and the Zoology Department of the University of Durham for the use of its facilities.

\section{References}

1. BORRADAII.E, I. J. B., M. J. B. GREEN, I.. C. MOON, P. J. ROBINSON and A. TAIT 1977. I angtang National Park management plan. Durham University Himalayan Expedition in collab. with National Parks and Wildlife Conservation Project, Kathmandu.

2. CAUGHI.EY, G. 1969. Wildlife and recreation in the Trisuli Watershed and other areas in Nepal. FAO/UNDP Project Report No. 6, Kathmandu.

3. FOX, J. L. 1974. An ecological survey of the proposed Langtang National Park. National Parks and Wildlife Conservation Project, Kathmandu (unpublished).

4. GOODWIN, H., and C. W. HOI,I OWAY 1972. IUCN Red Data Book, Mammalia.

5. GREEN, M. J. B. 1978. The ecology and feeding behaviour of the Himalayan tahr (Hemitragus jemlahicus) in the Langtang Valley, Nepal. MSc thesis, Univ. of Durham.

6. HOI,MES, J. R. S. 1970. A note on Himalayan tahr. f. Bombay Nat. Hist. Soc. 67: $103-5$.

7. KURTEN, B. 1968. Pleistocene Mammals of Europe. Weidenfeld and Nicolson, I.ondon.

8. PRATER, S. H. 1971. The Book of Indian Animals, third (revised) edition. Bombay Nat. Hist. Soc., Bombay.

9. SCHAFER, V. 1950. Uber den Schapi (Hemitragus jemlahicus schaeferi) Zool. Anzeiger 145: 247-60.

10. SCHALLER, G. B. 1973. Observations on Himalayan tahr (Hemitragus jemlahicus). F. Bombay Nat. Hist. Soc. 70: 1-24.

11.

1977. Mountain Monarchs. Univ. Chicago Press, Chicago.

12. STOCKI.EY, C. 1928. Big Game Shooting in the Indian Empire. Constable, I.ondon.

Michael J. B. Green, Department of Applied Biology, Pembroke Street, Cambridge CB2 3BX. 